\title{
Restoration of miR-517a expression induces cell apoptosis in bladder cancer cell lines
}

\author{
TAKAYUKI YOSHITOMI ${ }^{1}$, KAZUMORI KAWAKAMI $^{1}$, HIDEKI ENOKIDA $^{1}$, TAKESHI CHIYOMARU $^{1}$, \\ ICHIRO KAGARA ${ }^{1}$, SHUICHI TATARANO ${ }^{1}$, HIROFUMI YOSHINO ${ }^{1}$, HIROSHI ARIMURA ${ }^{1}$, \\ KENRYU NISHIYAMA ${ }^{1}$, NAOHIKO SEKI ${ }^{2}$ and MASAYUKI NAKAGAWA ${ }^{1}$ \\ ${ }^{1}$ Department of Urology, Graduate School of Medical and Dental Sciences, Kagoshima University, Kagoshima; \\ ${ }^{2}$ Department of Functional Genomics, Graduate School of Medicine, Chiba University, Chiba, Japan
}

Received December 13, 2010; Accepted January 31, 2011

DOI: $10.3892 / o r .2011 .1253$

\begin{abstract}
The aim of this study was to find novel tumor suppressor microRNAs through screening genes epigenetically silenced by methylation in bladder cancer $(B C)$ cell lines using microRNA microarrays. Since miR-517a and miR-520g, both located on chromosome 19q13.42, were found to highly up-regulated genes after treatment with a demethylating agent, 5-aza-2'-deoxycytidine (5-Aza-dc), we hypothesized that they are tumor-suppressor microRNAs and performed a gain-offunction study using these mature microRNAs. The miR-517a restoration showed significant inhibition of cell proliferation in the transfectants compared to miR-control-transfected cells ( $p<0.0001$ both in BOY and T24 cells). Furthermore, ectopic overexpression of miR-517a markedly induced apoptosis in the miR-517a-transfected BC cell lines. In addition, we carried out oligo microarray analysis using miR-517a transfectants and miR-control transfectants (BOY and T24), from which 35 downregulated genes and 19 up-regulated genes were identified. These included amphiregulin (AREG) and BCL2-associated transcription factor 1, transcript variant 1 (BCLAF1), previously reported to be concerned with apoptosis, in both cell lines by miR-517a restoration. These data suggest that $\mathrm{miR}-517 \mathrm{a}$ functions as a tumor suppressor through inhibition of cell proliferation and induction of apoptosis under the regulation of $A R E G$ and/or $B C L A F 1$ in BC cells. Anti-apoptotic effects may be maintained by down-regulation of miR-517a due to DNA hypermethylation in human BC cells, suggesting that restoration of miR-517a may be a novel therapeutic strategy for human BC.
\end{abstract}

\section{Introduction}

Bladder cancer (BC) is the fifth most common malignancy worldwide, and it is the second most common cause of death

Correspondence to: Dr Kazumori Kawakami, Department of Urology, Graduate School of Medical and Dental Sciences, Kagoshima University, 8-35-1 Sakuragaoka, Kagoshima 890-8520, Japan

E-mail:kkawakam@m.kufm.kagoshima-u.ac.jp

Key words: bladder cancer, miR-517a, apoptosis in patients with urological malignancy (1). Although the exact mechanism of bladder carcinogenesis is still unclear, some oncogenes and tumor suppressor genes have been suggested to play important roles in bladder tumorigenesis (2). Recently, it has been reported that microRNAs may act as oncogenes or tumor suppressors in BC (3).

microRNAs are small non-coding RNAs of 20-22 nucleotides and involved in crucial biological processes, including development, differentiation, apoptosis and proliferation (4-6) through imperfect pairing with target messenger RNAs (mRNAs) of protein-coding genes and the transcriptional or post-transcriptional regulation of their expression (7-9). It has also been shown that microRNAs are aberrantly expressed or mutated in cancers, as described above, suggesting that they may play a role as a novel class of oncogene or tumor suppressor gene, depending on the targets they regulate (10).

Recent studies have also established that methylation-mediated silencing of tumor suppressor genes (TSGs) play a crucial role in carcinogenesis (11). Because the down-regulation of many known TSGs in human cancer has been tightly linked to the hypermethylation of $\mathrm{CpG}$ sites located within $\mathrm{CpG}$ islands with promoter activity, the same mechanism could play an important role in the silencing of tumor-suppressive microRNAs in tumors (12). There is increasing evidence of epigenetic silencing of tumor-suppressive microRNAs, e.g. miR-137 in colorectal cancer (13), miR-141/200c in breast cancer (14), miR-9 in renal cell cancer (15), miR-196b in gastric cancer (16), miR-145 in prostate cancer (17), and miR-124 in cervical cancer (18). This prompted us to screen for tumor-suppressive microRNAs silenced epigenetically in human BC, because such studies are lacking.

Therefore, we performed microRNA expression analysis using two BC cell lines before and after treatment with a demethylating agent, 5-aza-2'-deoxycytidine (5-Aza-dc). Since we found that the expression of miR-517a and miR-520g were highly restored by 5-Aza-dc treatment, we hypothesized that these microRNAs function as a tumor suppressor in BC cells. To test this hypothesis, we performed a gain-of-function study using these two mature microRNAs in BC cell lines. The miR-517a restoration significantly inhibited cell proliferation and markedly induced apoptosis in BC cell lines. In addition, we identified genes up- and down-regulated by miR-517a over- 
expression using the miR-517a transfectants and miR-control transfectants with an oligo microarray containing $\sim 44,000$ genes.

\section{Materials and methods}

$B C$ cell lines and cell culture. We used two human BC cell lines, BOY and T24. BOY was established in our laboratory from an Asian male patient aged 66 years diagnosed with stage III BC with lung metastasis (19). T24 was obtained from the American Type Culture Collection (ATCC, Manassas, VA, USA). These cell lines were maintained in minimum essential medium (MEM) supplemented with $10 \%$ fetal bovine serum in a humidified atmosphere of $5 \% \mathrm{CO}_{2}$ and $95 \%$ air at $37^{\circ} \mathrm{C}$.

5-Aza-dc treatment and microRNA transfection. The two $\mathrm{BC}$ cell lines were incubated with $10 \mu \mathrm{M}$ of 5 -Aza-dc (Sigma-Aldrich, St. Louis, MO, USA) for four days. Culture medium and 5-Aza-dc were replaced every two days. For the gain-of-function study, the cell lines were transfected using RNAiMax transfection reagent (Invitrogen, Carlsbad, CA, USA) and Opti-MEM ${ }^{\mathrm{TM}}$ (Invitrogen) with $10 \mathrm{nM}$ of mature microRNA molecules, miR-control, miR-517a and miR-520g, (cat. no.: AM17111, PM12660, PM10365, respectively; Ambion, Austin, TX, USA). Cells were seeded in a 96-well plate for the XTT assay $(3,000$ cells per well) or in a 6-well plate for the apoptosis assay $\left(2 \times 10^{5}\right.$ cells per well).

RNA extraction. Total RNA, including microRNA for the microRNA microarray was extracted from BC cell lines before and after the 5-Aza-dc treatment using the mirVana ${ }^{\mathrm{TM}}$ microRNA isolation kit (Ambion) in accordance with the manufacturer's protocol. Total RNA for the oligo microarray was extracted from the two cell lines transfected with either miR-control or miR-517a using an ISOGEN ${ }^{\mathrm{TM}}$ kit (Nippon Gene, Tokyo, Japan) in accordance with the manufacturer's protocol.

microRNA expression signatures and data normalization. microRNA expression patterns were evaluated using the TaqMan Low Density Array Human MicroRNA Panel v2.0 (Applied Biosystems, Foster City, CA). The assay was composed of two steps: generation of cDNA by reverse transcription and a TaqMan real-time PCR assay. Briefly, microRNAs in the samples were converted to cDNA using 665 specific stem-loop reverse transcription primers. After cDNA conversion, the quantity of mature microRNA was evaluated using specific TaqMan real-time PCR primers and probes. Real-time PCR was performed in duplicate using GeneAmp Fast PCR Master Mix (Applied Biosystems) and the ABI 7900HT Real-Time PCR System (Applied Biosystems). The comparative CT method $(\Delta-\Delta \mathrm{CT})$ was used to determine expression levels of the mature mRNAs. Description of real-time PCR and the list of human microRNAs can be found on the company's website (http://www.appliedbiosystems.com). Analysis of relative microRNA expression data was performed using GeneSpring GX version 7.3.1 software (Agilent Technologies) in accordance with the manufacturer's instructions. We used two different approaches for normalizing the microRNA expression data, endogenous gene normalization based on $R N U 48$ and global normalization.

Quantitative real-time RT-PCR. Quantifications of miR-517a and miR-520g expression levels in BC cells before and after the 5-Aza-dc treatment and in human normal bladder (cat. no.: AM7990, Ambion) were assessed by stem-loop RT-PCR (TaqMan ${ }^{\circledR}$ MicroRNA Assays, Applied Biosystems) in accordance with the manufacturer's recommendations. RNU48 was used as an internal control. Aliquots of total RNA $(1 \mu \mathrm{g})$ from miR-control, miR-517a, or miR-520g transfectant were converted into cDNA using a high-capacity cDNA reverse transcription kit (Applied Biosystems) in accordance with the manufacturer's protocol. Quantitative TaqMan RT-PCR (qRTPCR) was performed using TaqMan primers for amphiregulin (AREG) and BCL2-associated transcription factor 1, transcript variant 1 (BCLAF1) with miR-control- and miR-517a transfectants. GUSB was used as an internal control. All quantitative RT-PCRs were performed using a 7300 Real-Time PCR System (Applied Biosystems) following the manufacturer's protocol. All reactions were performed in triplicate and $\Delta-\Delta$ $\mathrm{Ct}$ methods were used to calculate the fold change.

Cell viability assay. Cell viability was determined using an XTT assay (Roche Applied Sciences, Tokyo, Japan) at $72 \mathrm{~h}$ after transfection in accordance with the manufacturer's protocol. All experiments were performed in triplicate. Photographs (x100) of the cells in 6-well dishes were also taken with a light microscope at $72 \mathrm{~h}$ after transfection.

Analysis of apoptosis. BC cell lines transiently transfected with transfection reagent only (mock), miR-control, or miR517a in 6-well tissue culture plates as described above, were harvested $48 \mathrm{~h}$ after transfection by trypsinization. Double staining with FITC-Annexin V and PI was carried out using the FITC-Annexin V Apoptosis Detection Kit (BD Biosciences, Franklin Lakes, NJ, USA), in accordance with the manufacturer's recommendations and immediately analyzed within $1 \mathrm{~h}$ by flow cytometer (FACScan ${ }^{\circledR}$; BD Biosciences). Cells were discriminated into viable cells, dead cells, early apoptotic cells, and apoptotic cells by the CellQuest software (BD Biosciences), and then the percentages of early apoptotic cells plus apoptotic cells from each experiment were compared. Experiments were done in triplicate.

Screening of up- or down-regulated genes by miR-517a transfection. Oligo-microarray Human 44K (Agilent) was used for expression profiling in miR-517a-transfectans (BOY and T24) in comparison with miR-control transfectant in accordance with the manufacturer's protocol as previously described (19). Amphiregulin (AREG) and BCL2-associated transcription factor 1, transcript variant 1 (BCLAF1), one of the down- and up-regulated genes, respectively, commonly in the two cell lines were validated by quantitative real-time RT-PCR. Entries from the current microarray data were approved by the gene expression omnibus (GEO) and were assigned GEO accession no. (GSE19717).

Statistical analysis. Data are shown as mean values \pm standard deviation (SD). The relationship between two variables 
Table I. Top 20 up-regulated microRNAs by 5-Aza-dc treatment.

\begin{tabular}{|c|c|c|c|c|}
\hline \multirow[b]{2}{*}{ microRNA } & \multicolumn{3}{|c|}{ Fold change } & \multirow[b]{2}{*}{ Map location } \\
\hline & BOY & $\mathrm{T} 24$ & Average & \\
\hline miR-520g & 2.40 & 103.22 & 52.81 & $19 q 13.42$ \\
\hline $\operatorname{miR}-517 a$ & 19.64 & 79.44 & 49.54 & $19 q 13.42$ \\
\hline miR-7 & 64.85 & 18.52 & 41.68 & $9 \mathrm{q} 21.32,15 \mathrm{q} 26.1,19 \mathrm{p} 13.3$ \\
\hline miR-941 & 5.36 & 71.57 & 38.47 & $20 \mathrm{q} 13.33$ \\
\hline $\operatorname{miR}-454^{*}$ & 2.50 & 50.89 & 26.69 & $17 \mathrm{q} 22$ \\
\hline $\operatorname{miR}-629^{*}$ & 45.52 & 6.40 & 25.96 & $15 q 23$ \\
\hline miR-497 & 2.54 & 41.33 & 21.93 & $17 \mathrm{p} 13.1$ \\
\hline $\operatorname{miR}-520 c-3 p$ & 2.06 & 37.68 & 19.87 & $19 q 13.42$ \\
\hline $\operatorname{miR}-548 d-5 p$ & 16.43 & 16.06 & 16.25 & $8 \mathrm{q} 24.13$ \\
\hline miR-409-3p & 10.24 & 19.70 & 14.97 & $14 q 32.31$ \\
\hline $\operatorname{miR}-542-5 p$ & 4.89 & 22.61 & 13.75 & $\mathrm{Xq} 26.3$ \\
\hline miR-423-5p & 16.06 & 8.62 & 12.34 & $17 q 11.2$ \\
\hline miR-192* & 20.45 & 3.74 & 12.10 & $11 \mathrm{q} 13.1$ \\
\hline miR-491-3p & 8.59 & 9.32 & 8.96 & $9 \mathrm{p} 21.3$ \\
\hline $\operatorname{miR}-342-5 p$ & 9.87 & 4.57 & 7.22 & $14 q 32.2$ \\
\hline miR-650 & 2.42 & 10.53 & 6.47 & $22 q 11.22$ \\
\hline $\operatorname{miR}-215$ & 2.48 & 9.42 & 5.95 & $1 \mathrm{q} 41$ \\
\hline miR-597 & 3.18 & 8.35 & 5.77 & $8 \mathrm{p} 23.1$ \\
\hline miR-486-5p & 2.92 & 6.54 & 4.73 & $8 \mathrm{p} 11.21$ \\
\hline miR-27b* & 4.92 & 3.33 & 4.12 & $9 \mathrm{q} 22.32$ \\
\hline
\end{tabular}

and the numerical values obtained by real-time RT-PCR was analyzed using the Mann-Whitney $U$ test. The relationship between three variables was analyzed using the Bonferroniadjusted Mann-Whitney U test. Expert StatView ${ }^{\circledR}$ analysis software (version 4; SAS Institute Inc., Cary, NC, USA) was used in both cases.

\section{Results}

miR-517a and miR-520g are up-regulated after 5-Aza-dc treatment in $B C$ cell lines. The microRNA expression signatures demonstrated that a total of 34 microRNAs were commonly up-regulated $>2$-fold in the two cell lines after 5-Aza-dc treatment. The top 20 up-regulated microRNAs are listed in Table I. Interestingly, the top two microRNAs of the list (miR-517a and miR-520g) are closely located in the same chromosome 19 microRNA cluster (C19MC). Using the stem-loop RT-PCR method, we confirmed that the two microRNAs were up-regulated after 5-Aza-dc treatment as shown in Fig. 1A. Moreover, we found that miR-517a and miR-520g expression levels in the $\mathrm{BC}$ cell lines were originally lower than those of the normal human bladder without 5-Aza-dc treatment (Fig. 1B).

miR-517a restoration significantly inhibits cell proliferation in $B C$ cell lines. We transfected the BC cell lines with miR-517a and miR-520g and evaluated their effect on cell viability. As shown in Fig. 2A, BC cell viability was significantly decreased in miR-517a-transfected cells compared to those transfected with mock or miR-control (BOY, $53.9 \pm 2.7 \%, 101.9 \pm 6.5 \%$ and $100.0 \pm 4.5 \%$, respectively, $\mathrm{p}<0.0001 ; \mathrm{T} 24,54.5 \pm 2.8 \%$, $103.3 \pm 6.3 \%$ and $100.0 \pm 5.2 \%$, respectively, $\mathrm{p}<0.0001)$ but not decreased by miR-520g at $72 \mathrm{~h}$ after transfection. As shown in Fig. 2A, miR-517a transfectants were sparse and less dense than mock or miR-control transfectants at $72 \mathrm{~h}$ after transfection (Fig. 2B).

miR-517a transfection induces apoptosis in BC cell lines. Because miR-517a significantly inhibited BC cell proliferation, we evaluated the effect of miR-517a over-expression on apoptosis by flow cytometry at $48 \mathrm{~h}$ after transfection. As shown in Fig. 3A as representative results, the apoptotic cell fractions (early apoptotic cells + apoptotic cells) were greater in miR-517a transfectants than in mock and miR-control transfectants (BOY, 16.68, 1.06 and 1.04\%, respectively; T24, $22.11,2.25$ and $2.36 \%$, respectively). The apoptotic cell fractions obtained from triplicate experiments in the miR-517a transfectants were significantly greater than those in the mocks and miR-control transfectants (relative to miR-control; BOY, $11.80 \pm 0.53,1.40 \pm 0.67$ and $1.00 \pm 0.27$, respectively, $\mathrm{p}<0.0001 ; \mathrm{T} 24,5.67 \pm 0.11,1.20 \pm 0.55$ and $1.00 \pm 0.33$, respectively, p<0.0001; Fig. 3B). At first, we tried to carry out an apoptosis assay at $72 \mathrm{~h}$ after transfection as done in the XTT assay, but the cells were too few to analyze at $72 \mathrm{~h}$ after miR517 a transfection.

Gene expression profiles of differentially expressed genes after miR-517a transfection. To find which genes are involved in inhibition of cell proliferation and/or in promotion of 
A

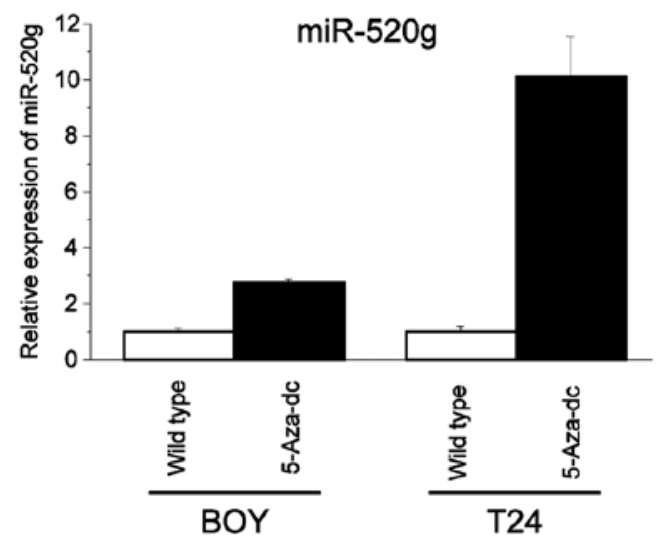

B

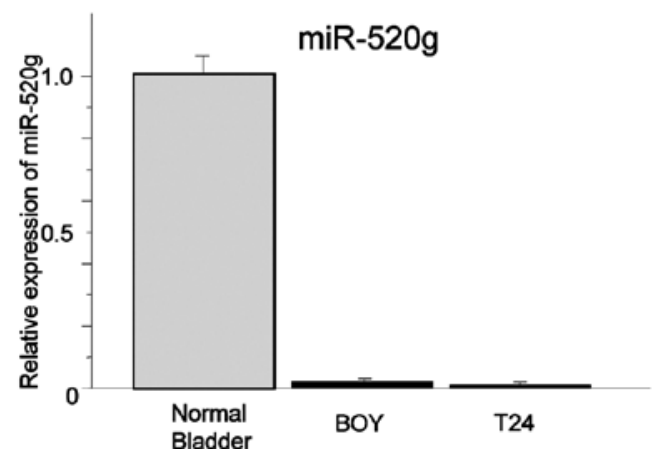

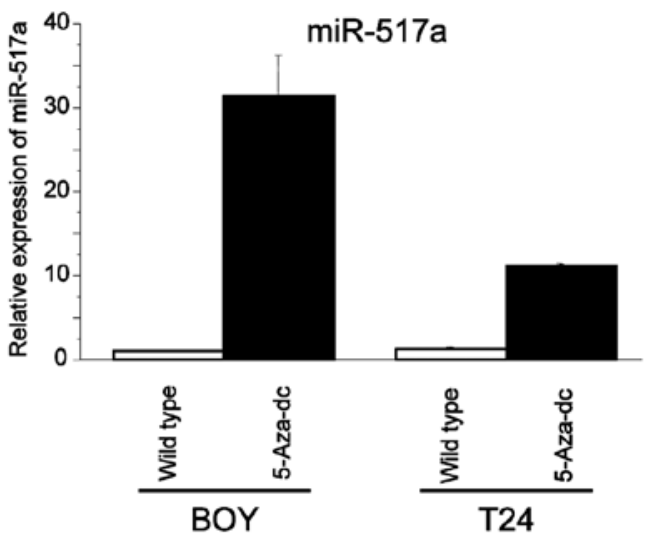

$\operatorname{miR}-517 a$

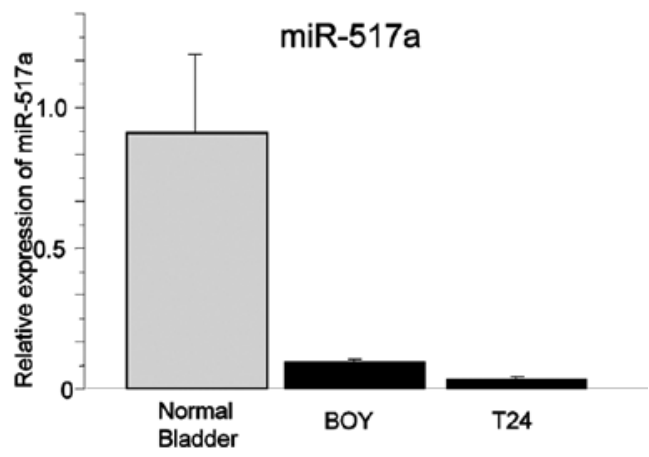

Figure 1. miR-517a and miR-520g expression in BC cell lines quantified by stem-loop real-time RT-PCR. (A) The expression levels of miR-517a and miR-520g were markedly up-regulated following 5-Aza-dc treatment in BC cell lines. (B) The expression levels of miR-517a and miR-520g were originally lower in BC cell lines than in human normal bladder.
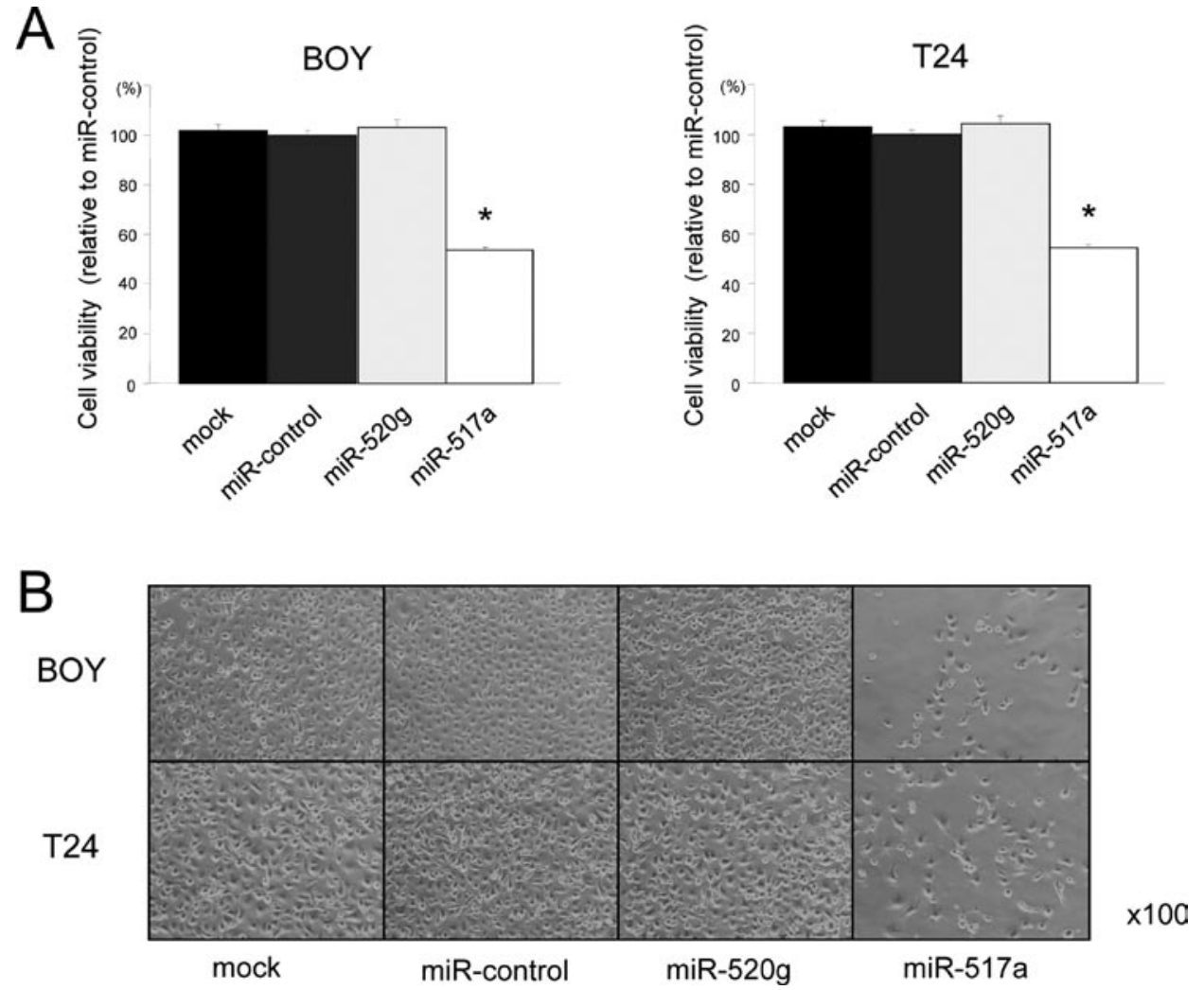

Figure 2. Repression of cell proliferation by miR-517a transfection in BC cell lines. (A) Effect of miR-517a and miR-520g transfection on the viability of BC cell lines in XTT assay ("p<0.0001). (B) Effect of miR-517a transfection on the morphology of BC cell lines. Photographs (x100) of mock, miR-control transfectants and miR-517a transfectants at $72 \mathrm{~h}$ after transfection are shown. 

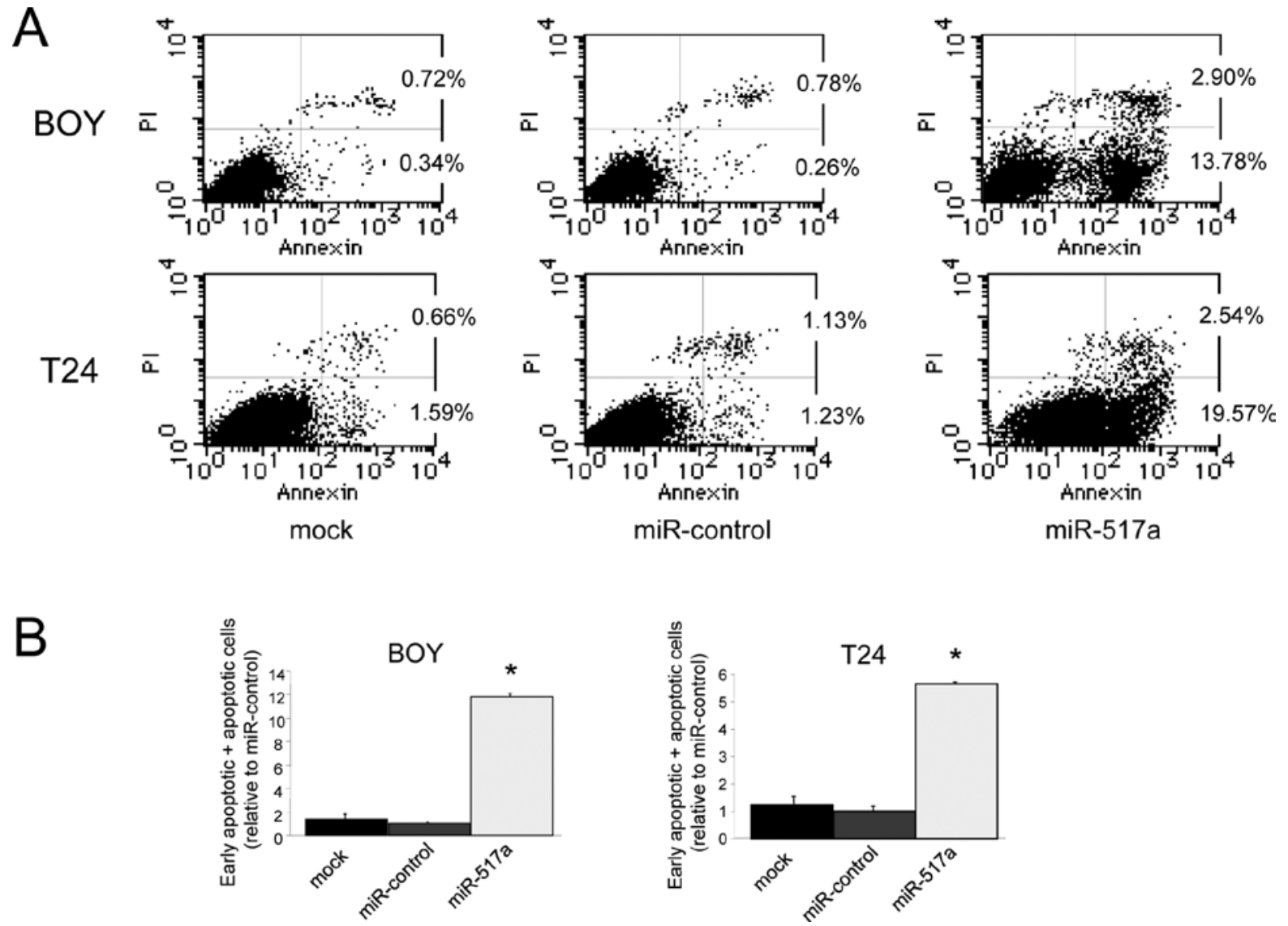

Figure 3. Effect of miR-517a transfection on apoptosis in BC cell lines. (A) Annexin V/PI staining discriminates between cells in early (lower right quadrant) and advanced (upper right quadrant) apoptotic states. Viable cells are double negative (lower left quadrant). The representative quadrant cell fractions in mock, miR-control transfectants and miR-517a transfectants are shown. (B) Ratio of the apoptotic cell fractions (early apoptotic + apoptotic cells) in miR-517a transfectants in comparison with mock and miR-control transfectant. The data for the apoptotic cell fractions are expressed as the relative value of the average expression of the miR-control transfectant.
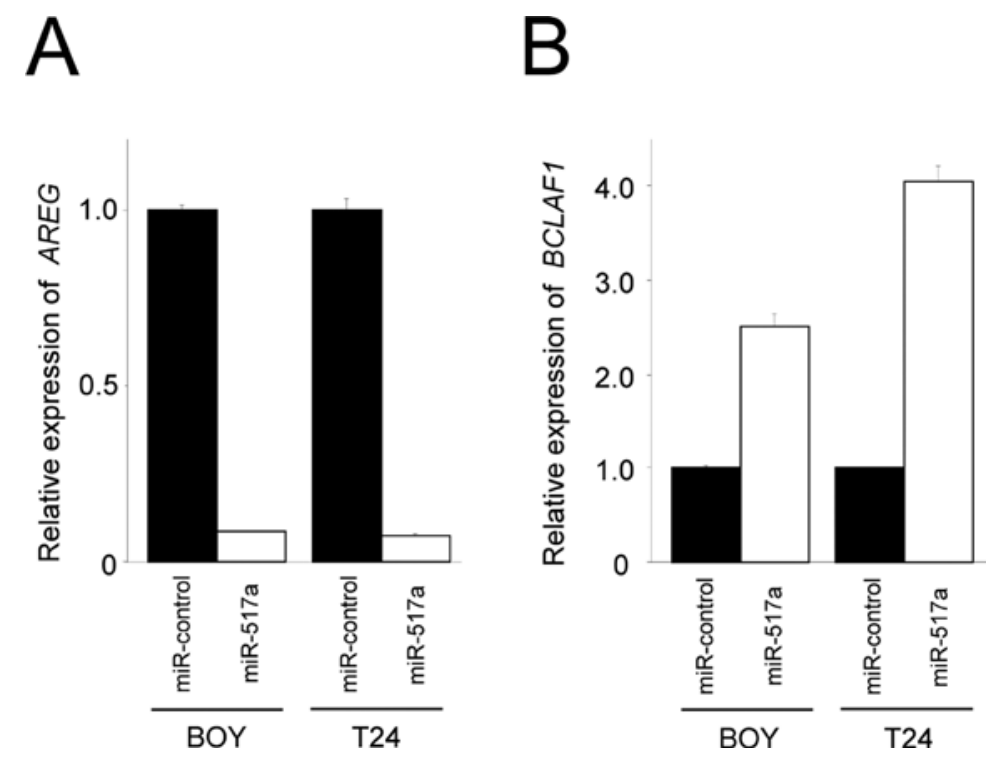

Figure 4. Validation of oligo-microarray data by real-time RT-PCR. (A) AREG was down-regulated in miR-517a transfectants compared to that in miRcontrol transfectant. (B) $B C L A F 1$ was up-regulated in miR-517a transfectants compared to that in miR-control transfectant.

apoptosis in $\mathrm{BC}$ cells, we performed an oligo-microarray consisting of 44,000 genes using miR-517a transfectants in comparison with the miR-control transfectant. The down- and up-regulated genes in the miR-517a transfectant $<-2.0$ - and 
Table II. Down-regulated genes in the miR-517a transfectant.

\begin{tabular}{|c|c|c|c|c|}
\hline \multirow[b]{2}{*}{ Gene symbol } & \multirow[b]{2}{*}{ Description } & \multicolumn{3}{|c|}{$\begin{array}{c}\log 2 \text { ratio } \\
\text { (miR-517a/miR-control) }\end{array}$} \\
\hline & & BOY & $\mathrm{T} 24$ & Average \\
\hline$A R E G$ & Amphiregulin (schwannoma-derived growth factor) & -3.29 & -4.07 & -3.68 \\
\hline CTSZ & Cathepsin Z & -3.55 & -2.98 & -3.26 \\
\hline$C D K 2 A P 1$ & CDK2-associated protein 1 & -3.20 & -3.32 & -3.26 \\
\hline CIQTNF5 & $\mathrm{C} 1 \mathrm{q}$ and tumor necrosis factor-related protein 5 & -3.19 & -3.33 & -3.26 \\
\hline FARPl & FERM, RhoGEF (ARHGEF) and pleckstrin domain protein , transcript variant 1 & -3.35 & -2.72 & -3.03 \\
\hline AGPAT3 & 1-acylglycerol-3-phosphate $\mathrm{O}$-acyltransferase 3 , transcript variant 1 & -3.24 & -2.46 & -2.85 \\
\hline SERF1B & Small EDRK-rich factor 1B (centromeric) & -3.10 & -2.53 & -2.82 \\
\hline ADAM9 & ADAM metallopeptidase domain 9 (meltrin $\gamma)$ & -2.75 & -2.84 & -2.79 \\
\hline C10orf114 & Chromosome 10 open reading frame 114 & -3.43 & -2.14 & -2.78 \\
\hline SLC25A23 & Solute carrier family 25 (mitochondrial carrier; phosphate carrier), member 23 & -2.97 & -2.52 & -2.74 \\
\hline TARSL2 & Threonyl-tRNA synthetase-like 2 & -3.10 & -2.34 & -2.72 \\
\hline$A E S$ & Amino-terminal enhancer of split, transcript variant 1 & -3.16 & -2.24 & -2.70 \\
\hline$A B H D 14 B$ & Abhydrolase domain containing 14B & -2.69 & -2.40 & -2.54 \\
\hline CNN2 & Calponin 2, transcript variant 1 & -2.81 & -2.24 & -2.53 \\
\hline$C C D C 113$ & Coiled-coil domain containing 113 & -2.42 & -2.61 & -2.51 \\
\hline$B 4 G A L T 2$ & $\beta$ GlcNAc $\beta$ 1,4-galactosyltransferase, polypeptide 2 , transcript variant 2 & -2.83 & -2.13 & -2.48 \\
\hline TCEAL1 & Transcription elongation factor A (SII)-like 1, transcript variant 3 & -2.67 & -2.24 & -2.46 \\
\hline$A P 1 S 2$ & Adaptor-related protein complex $1, \sigma 2$ subunit & -2.74 & -2.14 & -2.44 \\
\hline ATP6VIE2 & ATPase, $\mathrm{H}^{+}$transporting, lysosomal $31 \mathrm{kDa}, \mathrm{V} 1$ subunit $\mathrm{E} 2$ & -2.80 & -2.08 & -2.44 \\
\hline PREPL & Prolyl endopeptidase-like, transcript variant $\mathrm{C}$ & -2.37 & -2.49 & -2.43 \\
\hline PAQR9 & Progestin and adipoQ receptor family member IX & -2.29 & -2.56 & -2.43 \\
\hline REEP5 & Receptor accessory protein 5 & -2.73 & -2.07 & -2.40 \\
\hline$D B N 1$ & Drebrin 1 , transcript variant 2 & -2.61 & -2.18 & -2.39 \\
\hline SIPAIL3 & Signal-induced proliferation-associated 1 like 3 & -2.13 & -2.45 & -2.29 \\
\hline MAPK6 & Mitogen-activated protein kinase 6 & -2.12 & -2.44 & -2.28 \\
\hline$W S B 2$ & WD repeat and SOCS box-containing 2 & -2.50 & -2.06 & -2.28 \\
\hline RPS6KA4 & Ribosomal protein S6 kinase, $90 \mathrm{kDa}$, polypeptide 4, transcript variant 1 & -2.34 & -2.16 & -2.25 \\
\hline$M E S D C 1$ & Mesoderm development candidate 1 & -2.37 & -2.07 & -2.22 \\
\hline TTC15 & Tetratricopeptide repeat domain 15 & -2.40 & -2.01 & -2.21 \\
\hline FAM3A & Family with sequence similarity 3 , member A & -2.25 & -2.16 & -2.20 \\
\hline$S Q R D L$ & Sulfide quinone reductase-like (yeast) & -2.34 & -2.05 & -2.20 \\
\hline NTAN1 & $\mathrm{N}$-terminal asparagine amidase & -2.12 & -2.26 & -2.19 \\
\hline PPME1 & Protein phosphatase methylesterase 1 & -2.06 & -2.26 & -2.16 \\
\hline COL4A6 & Collagen, type IV, $\alpha 6$, transcript variant B & -2.16 & -2.12 & -2.14 \\
\hline C22orf9 & Chromosome 22 open reading frame 9 , transcript variant 1 & -2.13 & -2.02 & -2.08 \\
\hline
\end{tabular}

$>2.0$-fold $(\log 2$ ratio, each) both in BOY and T24 are listed in Tables II and III, respectively. To confirm the results of our oligo microarray data, we performed quantitative real-time RT-PCR using TaqMan primers for AREG and BCLAF1, one of the down- and up-regulated genes, respectively, since the two genes have been reported to be concerned with apoptosis in the literature. We found that $A R E G$ was down-regulated whereas $B C L A F 1$ was up-regulated in miR-157a-transfected BC cell lines compared to miR-control transfectant (Fig. 4). These results indicate that our oligo microarray data were reproducible.

\section{Discussion}

We found for the first time that miR-517a was down-regulated, and ectopic restoration of miR-517a significantly inhibited cell proliferation by promoting apoptosis in BC cell lines. We also demonstrated that miR-517a expression was markedly restored by 5 -Aza-dc treatment, but we did not detect hypermethylation of the miR-517a promoter region because, to our knowledge, there was no apparent $\mathrm{CpG}$ island within 2-k bases upstream of the miR-517a pre-microRNA sequence. miR-517a and miR-520g, examined in this study, are members of the chro- 
Table III. Up-regulated genes in the miR-517a transfectant.

\begin{tabular}{|c|c|c|c|c|}
\hline \multirow[b]{2}{*}{ Gene symbol } & \multirow[b]{2}{*}{ Description } & \multicolumn{3}{|c|}{$\begin{array}{c}\log 2 \text { ratio } \\
(\mathrm{miR}-517 \mathrm{a} / \mathrm{miR} \text {-control })\end{array}$} \\
\hline & & BOY & $\mathrm{T} 24$ & Average \\
\hline ANKRD46 & Ankyrin repeat domain 46 & 3.44 & 3.34 & 3.39 \\
\hline$B C L A F 1$ & BCL2-associated transcription factor 1 , transcript variant 1 & 3.33 & 2.99 & 3.16 \\
\hline RGS5 & Regulator of G-protein signalling 5 & 2.68 & 3.13 & 2.90 \\
\hline$A X L$ & AXL receptor tyrosine kinase, transcript variant 1 & 2.89 & 2.56 & 2.72 \\
\hline SGOL1 & Shugoshin-like 1 (S. pombe), transcript variant A2 & 3.32 & 2.07 & 2.69 \\
\hline PCGF5 & Homo sapiens polycomb group ring finger 5 (PCGF5) & 2.50 & 2.69 & 2.59 \\
\hline LYSMD3 & LysM, putative peptidoglycan-binding, domain containing 3 & 2.65 & 2.48 & 2.57 \\
\hline$I L 1 F 9$ & Interleukin 1 family, member 9 & 2.39 & 2.54 & 2.47 \\
\hline BIRC3 & Baculoviral IAP repeat-containing 3, transcript variant 1 & 2.19 & 2.67 & 2.43 \\
\hline SGOL2 & Shugoshin-like 2 (S. pombe) & 2.51 & 2.33 & 2.42 \\
\hline$N I P B L$ & Nipped-B homolog (Drosophila), transcript variant B & 2.11 & 2.65 & 2.38 \\
\hline DCTN5 & Dynactin 5 (p25) & 2.52 & 2.08 & 2.30 \\
\hline CEP135 & Centrosomal protein $135 \mathrm{kDa}$ & 2.31 & 2.23 & 2.27 \\
\hline$L C O R$ & Ligand-dependent nuclear receptor corepressor & 2.18 & 2.27 & 2.23 \\
\hline ICAMI & Intercellular adhesion molecule 1 & 2.22 & 2.09 & 2.16 \\
\hline RNASEL & Ribonuclease (2',5'-oligoisoadenylate synthetase-dependent) & 2.03 & 2.27 & 2.15 \\
\hline$R B B P 4$ & Retinoblastoma binding protein 4 & 2.22 & 2.05 & 2.14 \\
\hline$P E X 11 B$ & Peroxisomal biogenesis factor 11B & 2.07 & 2.15 & 2.11 \\
\hline PPFIA4 & Protein tyrosine phosphatase, receptor type, f polypeptide, interacting protein, $\alpha 4$ & 2.06 & 2.05 & 2.05 \\
\hline
\end{tabular}

mosome 19 microRNA cluster (C19MC). Tsai et al found that the C19MC expression pattern was highly correlated with the methylation status of a distal CpG-rich region located $\sim 17.6 \mathrm{~kb}$ upstream of the cluster (20). miR-517a and miR-520g might be down-regulated by methylation of this $\mathrm{CpG}$ island as reported because their expression was also restored by the 5-Aza-dc treatment in our study. Histone modification, also known as epigenetic alteration like DNA methylation, might be associated with the restoration of their expression since treatment with 5-Aza-dc changes not only the DNA methylation status but also the histone modifications to an active pattern in the promoter region $(21,22)$.

Among the two microRNAs selected by the microRNA array using BC cells before and after 5-Aza-dc treatment, only miR-517a restoration had a significant inhibitory effect on cell proliferation. Furthermore, it markedly induced apoptosis in the two BC cell lines tested while the reason why only miR517a has such a tumor-suppressive effect is unclear. miR-517a may up- or down-regulate some essential genes related to cell proliferation and/or apoptosis but miR-520g did not. On the basis of this hypothesis, we performed an oligo-microarray containing approximately 44,000 genes using BC cell lines (BOY and T24) transfected with miR-control or miR-517a. Thirty-five genes were down-regulated $<-2$-fold whereas 19 genes were up-regulated $>2$-fold ( $\log 2$ ratio, respectively) in miR-517a transfectants compared to miR-control transfectants (BOY and T24). Among them, AREG was found to be down-regulated while $B C L A F 1$ was up-regulated in miR-517a transfectant by real-time RT-PCR. Furthermore, $A R E G$ was found to have a putative target site in its 3'UTR region by referring to a commercial web database (TargetScanHuman; http:// www.targetscan.org/vert_50/), making it a candidate target gene for miR-517a.

$A R E G$ is a member of the epidermal growth factor (EGFR) family and a ligand of EGFR (23). AREG over-expression has been frequently observed in various types of human cancer such as colon, breast, prostate, pancreas and lung cancer (24-28). Busser et al recently reported that gefitinib-mediated apoptosis was reduced through AREG-mediated down-regulation of the proapoptotic protein BAX in non-small cell lung cancer (NSCLC) cells (29). It is possible that miR-517a causes inhibition of cell proliferation and/or promotes apoptosis by down-regulating AREG as its target gene.

$B C L A F 1$, also known as BCL-2-associated transcription factor $(B T F)$, was originally identified as a protein that interacts with anti-apoptotic members of the $\mathrm{Bcl} 2$ family. Initial studies indicated a role for $B C L A F 1$ as an inducer of apoptosis and a repressor of transcription (30). Liu et al reported that silencing of $B C L A F 1$ expression reduced TP53-dependent apoptosis, suggesting that TP53 is a downstream target of BCLAF1 and that BCLAF1 induces apoptosis in a TP53-dependent manner (31). miR-517a may inhibit cell proliferation and/or promote apoptosis by indirectly up-regulating $B C L A F 1$ in $\mathrm{BC}$ cell lines.

In conclusion, through screening up-regulated genes by 5-Aza-dc treatment, we found for the first time that miR-517a has tumor-suppressive function through inhibition of cell proliferation and induction of apoptosis in BC cell lines. 
Anti-apoptotic effect may be maintained by down-regulation of miR-517a due to DNA hypermethylation in human BC cells, suggesting that restoration of miR-517a may be a novel therapeutic strategy for human BC.

\section{Acknowledgments}

This research was partially supported by the Ministry of Education, Science, Sports and Culture, Grant-in-Aid for Scientific Research (B and C), 20390427 and 20591861, 2008. We thank Ms. Mutsumi Miyazaki for her excellent laboratory assistance.

\section{References}

1. Jemal A, Siegel R, Ward E, Hao Y, Xu J and Thun MJ: Cancer statistics, 2009. CA Cancer J Clin 59: 225-249, 2009.

2. Brandau S and Böhle A: Bladder cancer. I. Molecular and genetic basis of carcinogenesis. Eur Urol 39: 491-497, 2001.

3. Gottardo F, Liu CG, Ferracin M, et al: micro-RNA profiling in kidney and bladder cancers. Urol Oncol 25: 387-392, 2007.

4. Calin GA and Croce CM: microRNA signatures in human cancers. Nat Rev Cancer 6: 857-866, 2006.

5. Bartel DP: microRNAs: genomics, biogenesis, mechanism, and function. Cell 116: 281-297, 2004.

6. Harfe BD: microRNAs in vertebrate development. Curr Opin Genet Dev 15: 410-415, 2005.

7. Bartel DP and Chen CZ: Micromanagers of gene expression: the potentially widespread influence of metazoan microRNAs. Nat Rev Genet 5: 396-400, 2004.

8. Rajewsky N: microRNA target predictions in animals. Nat Genet 38: S8-S13, 2006.

9. Lim LP, Lau NC, Garrett-Engele P, et al: Microarray analysis shows that some microRNAs downregulate large numbers of target mRNAs. Nature 433: 769-773, 2005.

10. Iorio MV, Visone R, Di Leva $\mathrm{G}$, et al: microRNA signatures in human ovarian cancer. Cancer Res 15: 8699-8707, 2007.

11. Datta J, Kutay H, Nasser MW, et al: Methylation mediated silencing of microRNA-1 gene and its role in hepatocellular carcinogenesis. Cancer Res 68: 5049-5058, 2008.

12. Kozaki K, Imoto I, Mogi S, Omura K and Inazawa J: Exploration of tumor-suppressive microRNAs silenced by DNA hypermethylation in oral cancer. Cancer Res 68: 2094-2105, 2008.

13. Balaguer F, Link A, Lozano JJ, Cuatrecasas M, Nagasaka T, Boland CR and Goel A: Epigenetic silencing of miR-137 is an early event in colorectal carcinogenesis. Cancer Res 70: 6609-6618, 2010.

14. Neves R, Scheel C, Weinhold S, et al: Role of DNA methylation in miR-200c/141 cluster silencing in invasive breast cancer cells. BMC Res Notes 3: 219, 2010.

15. Hildebrandt MA, Gu J, Lin J, et al: Hsa-miR-9 methylation status is associated with cancer development and metastatic recurrence in patients with clear cell renal cell carcinoma. Oncogene 29: 5724-5728, 2010
16. Tsai KW, Hu LY, Wu CW, et al: Epigenetic regulation of miR-196b expression in gastric cancer. Genes Chromosomes Cancer 49: 969-980, 2010.

17. Zaman MS, Chen Y, Deng G, et al: The functional significance of microRNA-145 in prostate cancer. Br J Cancer 103: 256-264, 2010.

18. Wilting SM, van Boerdonk RA, Henken FE, et al: Methylationmediated silencing and tumour suppressive function of hsa-miR-124 in cervical cancer. Mol Cancer 9: 167, 2010.

19. Chiyomaru T, Enokida H, Tatarano S, et al: miR-145 and miR-133a function as tumour suppressors and directly regulate FSCN1 expression in bladder cancer. Br J Cancer 102: 883-891, 2010.

20. Tsai KW, Kao HW, Chen HC, Chen SJ and Lin WC: Epigenetic control of the expression of a primate-specific microRNA cluster in human cancer cells. Epigenetics 4: 587-592, 2009.

21. Kawamoto K, Hirata H, Kikuno N, Tanaka Y, Nakagawa M and Dahiya R: DNA methylation and histone modifications cause silencing of Wnt antagonist gene in human renal cell carcinoma cell lines. Int J Cancer 123: 535-542, 2008.

22. Nguyen CT, Weisenberger DJ, Velicescu M, Gonzales FA, Lin JC, Liang $\mathrm{G}$ and Jones PA: Histone H3-lysine 9 methylation is associated with aberrant gene silencing in cancer cells and is rapidly reversed by 5-aza-2'-deoxycytidine. Cancer Res 62: 6456-6461, 2002.

23. Lamber EP, Horwitz AA and Parvin JD: BRCA1 represses amphiregulin gene expression. Cancer Res 70: 996-1005, 2010.

24. Normanno N, De Luca A, Bianco C, et al: Epidermal growth factor receptor (EGFR) signaling in cancer. Gene 366: 2-16, 2006.

25. Salomon DS, Normanno N, Ciardiello F, Brandt R, Shoyab M and Todaro GJ: The role of amphiregulin in breast cancer. Breast Cancer Res Treat 33: 103-114, 1995.

26. Bostwick DG, Qian J and Maihle NJ: Amphiregulin expression in prostatic intraepithelial neoplasia and adenocarcinoma: a study of 93 cases. Prostate 58: 164-168, 2004.

27. Ebert M, Yokoyama M,Kobrin MS, et al: Induction and expression of amphiregulin in human pancreatic cancer. Cancer Res 54: 3959-3962, 1994

28. Fontanini G, De Laurentiis M, Vignati S, et al: Evaluation of epidermal growth factor-related growth factors and receptors and of neoangiogenesis in completely resected stage I-IIIA non-small-cell lung cancer: amphiregulin and microvessel count are independent prognostic indicators of survival. Clin Cancer Res 4: 241-249, 1998.

29. Busser B, Sancey L, Josserand V, Niang C, Favrot MC, Coll JL and Hurbin A: Amphiregulin promotes BAX inhibition and resistance to gefitinib in non-small-cell lung cancers. Mol Ther 18: 528-535, 2010.

30. Kasof GM, Goyal L and White E: Btf, a novel death-promoting transcriptional repressor that interacts with Bcl-2-related proteins. Mol Cell Biol 19: 4390-4404, 1999.

31. Liu H, Lu ZG, Miki Y and Yoshida K: Protein kinase C delta induces transcription of the TP53 tumor suppressor gene by controlling death-promoting factor Btf in the apoptotic response to DNA damage. Mol Cell Biol 27: 8480-8491, 2007. 